\title{
Resonance Overvoltages in Medium-Voltage Multilevel Drive Systems
}

\author{
Frieder Endrejat, Senior Member, IEEE, and Pragasen Pillay, Fellow, IEEE
}

\begin{abstract}
Simulations and field tests indicate that unacceptable motor-terminal overvoltages and waveform shapes can occur in the normal operating range with high-output-voltage multilevel drive systems. These waveforms (if unattended) can result in premature motor insulation failures. A case study of an $11-\mathrm{kV}$ multilevel system is presented. Simulations and calculations confirm the theory of resonance overvoltages. Different solution possibilities are analyzed. Further simulations and investigations are performed to determine the optimal carrier frequency. Test results confirm that the proposed modification has the desired effect, with waveforms well within limits stipulated by international standards. Simplified equations and recommendations are provided to determine suitable application solutions. Further simulated resonance case studies are presented, considering the effect of the system configurations, motor size, and cable length. Suitable carrier-frequency selection methods are presented to solve the problem.
\end{abstract}

Index Terms-AC motor drives, equivalent circuits, harmonic analysis, load modeling, medium voltage (MV), overvoltage protection, resonance, rotating machine testing.

\section{INTRODUCTION}

$\mathbf{T}$ HE NUMBER and popularity of medium-voltage (MV) large multilevel adjustable-speed systems are rapidly increasing [1]-[3]. The advantages and application possibilities of the voltage-source-inverter (VSI) cascaded H-bridge topology are described in [1]-[6]. There has been a strong demand to build inverters at higher voltage levels $(11-16 \mathrm{kV})$ [2]. Most commercially available related current-source-inverter (CSI)and VSI-based drives have, until 2004, only been available for application voltages up to $7.2 \mathrm{kV}$ [1]. The VSI multilevel cascaded H-bridge (VSI-ML-H) technology, suitable for induction and synchronous motor applications, now exists at high power ratings (e.g., $>15 \mathrm{MW}$ ) and voltage levels but with very limited actual site application and operational experience. It has been shown that VSI-ML-H drives (at lower voltages) can be very reliable but that the failure of electrolytic capacitors

Paper PID-08-20, presented at the 2007 IEEE International Electric Machines and Drives Conference, Antalya, Turkey, May 3-5, and approved for publication in the IEEE TRANSACTIONS ON INDUSTRY APPLICATIONS by the Petroleum and Chemical Industry Committee of the IEEE Industry Applications Society. Manuscript submitted for review May 19, 2008 and released for publication January 26, 2009. First published May 19, 2009; current version published July 17, 2009. This work was supported by Sasol Technology.

F. Endrejat is with Sasol Technology, Secunda 2302, South Africa (e-mail: frieder.endrejat@sasol.com).

P. Pillay is with the Department of Electrical and Computer Engineering, Concordia University, Montreal, QC H3G 1M8, Canada, and also with the University of Cape Town, Rondebosch 7701, South Africa.

Color versions of one or more of the figures in this paper are available online at http://ieeexplore.ieee.org.

Digital Object Identifier 10.1109/TIA.2009.2023482 has resulted in drive trips before five years [7]. Film capacitors instead of electrolytic capacitors have been introduced in the dc bus of insulated-gate-bipolar-transistor (IGBT)-based inverters with an expected improvement in overall drive reliability. Highvoltage IGBTs are now used for high-power applications to minimize overall component counts but are associated with fewer and/or larger voltage steps when compared to the application of low-voltage IGBTs. Major industrial plants often have large existing motors at voltages $\geq 11-\mathrm{kV}$ level that may now benefit from the introduction of adjustable speed drives (ASDs) (e.g., for energy savings or process control) [8]. It is, however, important to investigate the possibility of potential overvoltages associated with the larger/fewer voltage steps.

This paper describes the output-voltage experience of the first 11-kV VSI-ML-H drive for multiple standard insulation synchronous motors at a major chemical and process plant. Specific attention is given to potential reflective-wave and resonance-induced overvoltage interactions between the drive and motor, which can be potentially damaging. The VSI-ML-H topology was selected for the application with $11-\mathrm{kV}$ outputvoltage capability even when one cell has failed. The selected topology has become popular for critical process industries benefiting from fault-tolerant operation and survivability advantages [8]. It must however be ensured that system availability, lifetime, and hazardous area requirements are not compromised due to insulation damage associated with inverter-induced overvoltages. Motor insulation requirements associated with MV ASDs are well documented in the literature and the recently published IEC 60034-18-42 standard [9], [10]. The standard (and literature) focuses, however, on the expected waveforms at the motor terminals, considering cable effects, MV pulsewidthmodulation (PWM) waveforms, and the reflective-wave phenomenon. It has been stated that the switching surges associated with VSI-ML-H systems are not likely to contribute to motor insulation problems due to the relatively small steps in voltage [12]. This was however based on low-voltage IGBT cells. Resonance overvoltages (not specifically addressed in IEC 60034-18-42) have been reported in literature for certain applications associated with significant voltage steps/surges. References [13] and [15] show that unacceptable motor-terminal resonance overvoltages can occur with a lower voltage twolevel inverter with a step-up transformer feeding an MV motor with a long cable distance. A filter [13] or alternative modulation strategy [15] was required to rectify the problem. Circuit breaker switching transients can excite resonance overvoltages at captive transformer-fed motors [16]. In CSI PWM systems, resonance can occur due to the inverter output capacitance and motor impedance, excited by drive harmonics. Typical solutions 


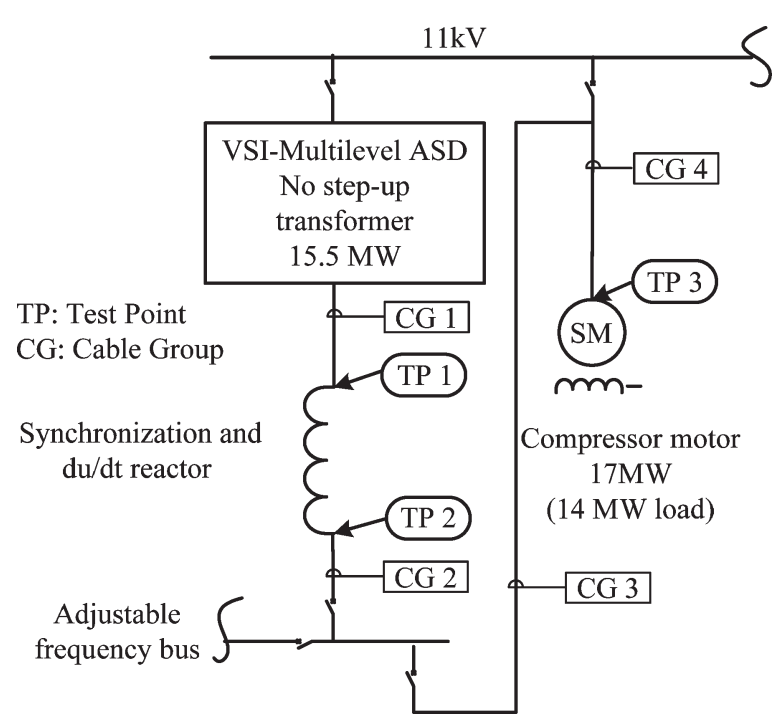

Fig. 1. Single-line diagram and test point locations (cable lengths and parameters are given in Table I).

include correct sizing of the capacitor and/or selective harmonic elimination [1].

This paper describes on-site measurements and simulations investigating the possibility of unacceptable overvoltages. The application configuration of the system is described in [8] and [11]. A synchronization, desynchronization, and process control scheme is applied to improve process availability (to synchronize the adjustable-speed-driven motor before certain drive trip conditions) and also to facilitate soft starting of other motors. A synchronization reactor is applied in applications with smooth make-before-brake transfers to limit the current during synchronization. This is also referred to as a bypass configuration. Further explanation for bypass configurations and current limitation during synchronization is described in [3], [11], and [14]. It is important to evaluate the effect of the rather uncommon synchronization reactor (normally not used with ASDs without a bypass configuration).

\section{INITIAL TESTS AND AsSESSMENT}

Tests were done to determine the maximum voltage, waveform shape, and maximum $d u / d t$ values at the motor terminals. Similar tests were performed before and after the synchronization reactor to determine the effect of the reactor and cables. Figs. 1-3 show the details of the test setup. Wideband voltage dividers with a high-voltage withstand capability were used in conjunction with a wideband oscilloscope. A capacitive voltage divider was selected due to its compactness and availability. The specifications for the test equipment are given in the Appendix. Additional tests were conducted by an independent consultant with a resistive divider circuit, with similar results.

Measurements were taken at 400, 800, 1200, and $1500 \mathrm{r} / \mathrm{min}$ (four-pole motor). The worst voltage peak-to-peak values and peak-to-earth values were recorded at $1200 \mathrm{r} / \mathrm{min}$ at the motor terminals. Furthermore, the system is designed for continuous operation between 1200 and $1500 \mathrm{r} / \mathrm{min}$. The results are therefore only shown for $1200 \mathrm{r} / \mathrm{min}$ in Fig. 4. The waveforms are displaced with respect to each other on the time axis for clarity.

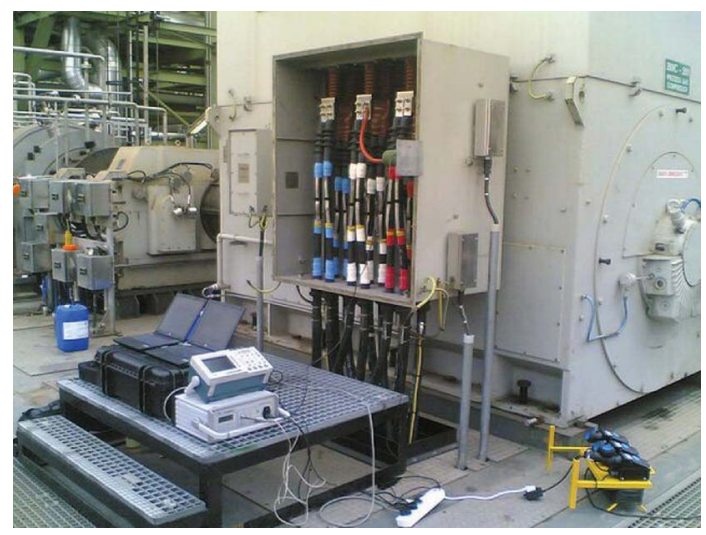

Fig. 2. Test setup at the motor terminals.

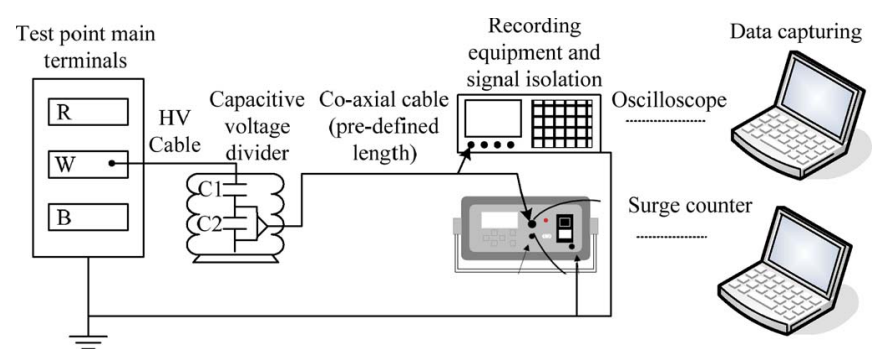

Fig. 3. Connection diagram of test setup (capacitive divider).

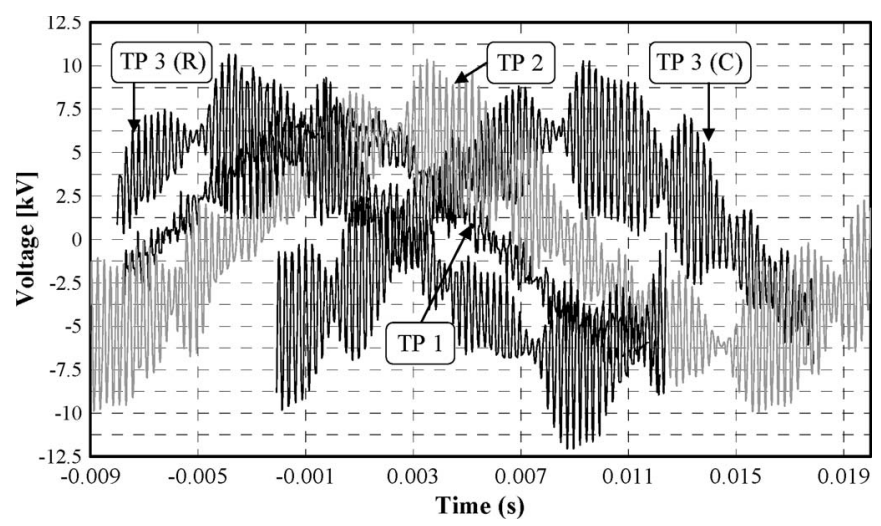

Fig. 4. Overview of voltage phase-to-earth waveforms at $40 \mathrm{~Hz}(1200 \mathrm{r} / \mathrm{min}$; $R$ : resistive divider; $C$ : capacitive divider).

The figure shows phase-to-earth voltage values for the reactor input, reactor output, motor terminals (from capacitor divider tests), and motor terminals (from resistive divider tests). The surge counter at the motor terminals did not record any pulses with rise times below $1.5 \mu \mathrm{s}$ (maximum rise time detectable by the pulse counter), confirming the filtering effect of the reactor.

\section{A. High-Frequency Traveling Waves}

The worst case $d u / d t$ values were recorded at the input of the reactor. Fig. 5 shows a higher resolution waveform, and the characteristic traveling-wave phenomenon is clearly visible. An even higher sampling rate is required to determine the $d u / d t$ rates as shown in Fig. 6. The recording is shown at nominal speed so that the maximum peak voltage at the input of the reactor is also shown. The traveling-wave phenomenon theory, simulations, and test results are well documented in the 


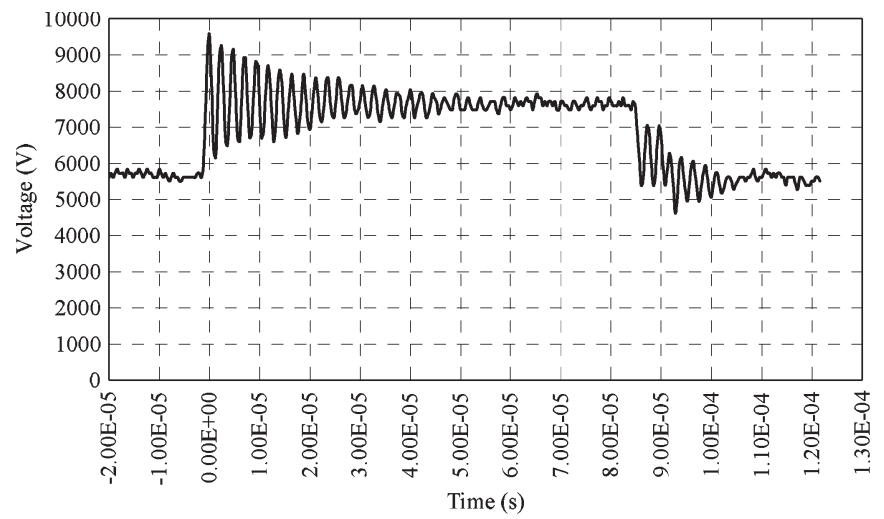

Fig. 5. Voltage phase-to-earth waveform at the input of the reactor (TP1, $1200 \mathrm{r} / \mathrm{min}$, higher sampling rate).

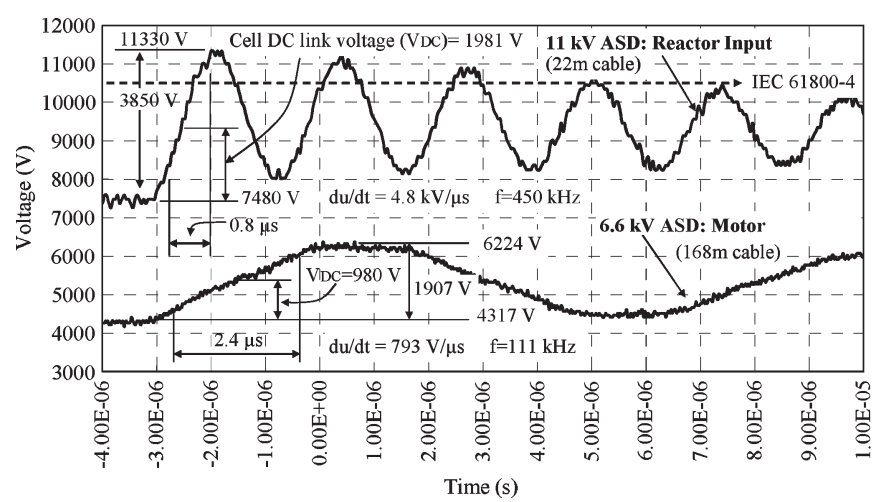

Fig. 6. Voltage phase-to-earth pulse waveforms (TP1, $1500 \mathrm{r} / \mathrm{min}$, maximum sampling rate) at the input of the reactor (11-kV system) and at motor terminals (6.6-kV system without reactor).

literature (see, e.g., [13], [16], [19], and [20]). In accordance with the theory, high-frequency traveling waves can be expected at the input of the reactor or at the motor terminals in the case of systems without reactors as shown in Fig. 6. The reactor and motor have highly inductive characteristics resulting in large load impedances and a reflection coefficient of approximately 1. Pulses in the multilevel steps can therefore be expected to double in initial amplitude, i.e., double the cell dc bus voltage as shown in Fig. 6.

The maximum allowable step value as per IEC 61800-4 (for interturn insulation) with rise times below $1 \mu \mathrm{s}$ is $3 \mathrm{kV}$. The rise time, $d u / d t$, and amplitude definitions in IEC 68000-4 are followed. The recordings at the reactor input show a maximum value of approximately $3.85 \mathrm{kV}$ with rise times below $1 \mu$ s (Fig. 6). Furthermore, according to IEC 61800-4 [17], a normal motor should be able to handle a maximum phase-to-earth voltage (main insulation) of $0.9 \times U_{\text {ins }}$ (rated insulation voltage), i.e., $0.9 \times 11.55 \mathrm{kV}=10.4 \mathrm{kV}$, whereas a maximum value of $11.33 \mathrm{kV}$ was recorded. Similar waveforms at the motor terminals for a system without a reactor may be expected, i.e., for a standard/old/existing motor insulation system interturn, withstand capability may have been a concern (in accordance with IEC 61800-4). IEC 60034-18-42 provides qualification procedures for new motors, and the recorded waveforms (without a reactor) can easily be managed. Motors fed from lower voltage VSI-ML-H drives (e.g., $6.6 \mathrm{kV}$ ) present a smaller concern due to the smaller voltage steps as shown

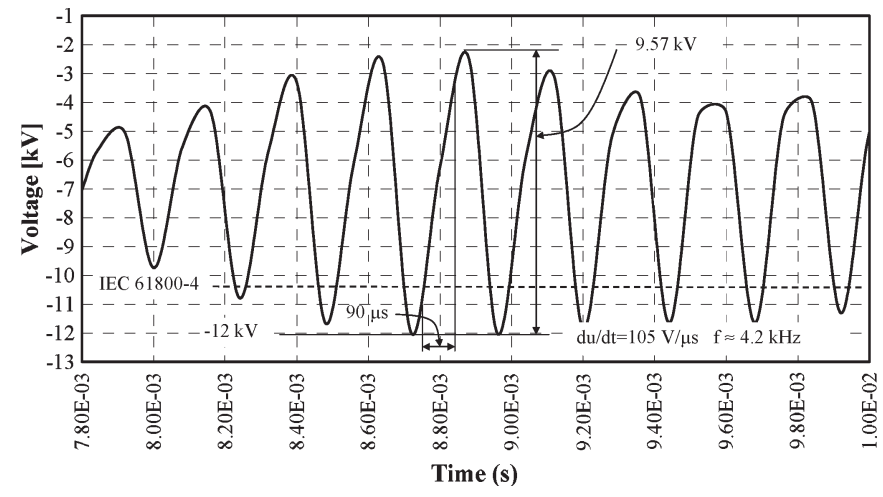

Fig. 7. Example of voltage phase-to-earth waveforms (TP3, $1200 \mathrm{r} / \mathrm{min})$ at the motor terminals.

in Fig. 6. The figure also shows that the oscillation frequency for the $6.6-\mathrm{kV}$ application with longer cable length is lower since the oscillation frequency reduces with an increase in cable length [19]. Longer cable lengths for higher voltage applications may therefore also present less severe cases due to a lower oscillation frequency and associated lower $d u / d t$ rates. The recorded values are, however, well within the capability of a custom-designed reactor with special insulation (withstand capability of $d u / d t=15 \mathrm{kV} / \mu$ s and a winding breakdown voltage of $17 \mathrm{kV}$ rms across the winding).

\section{B. Maximum Peak Values at Motor}

A far greater concern is the waveform shape and peak values recorded at the motor terminals as shown in Fig. 4 and with higher resolution in Fig. 7. The measurements show that the phase-to-earth levels in terms of IEC 61800-4 are exceeded, which can lead to premature motor failure since the motors do not have increased voltage withstand capability. The qualifying procedures in IEC 60034-18-42 do not specifically address resonance conditions for standard motors. The motor manufacturer has confirmed that the waveforms are unacceptable. Pulse evaluation curves shown in [18] confirm that accelerated aging can be expected based on the measured waveforms. This paper therefore focuses on this applicable overvoltage phenomenon (which does not represent the characteristic travelling waves).

\section{Modeling, Simulation, Explanation, AND SOLUTIONS}

\section{A. Inverter Modeling}

The inverter topology is shown in Fig. 8 (the rated voltage for each cell is $1375 \mathrm{~V}$, with a cell dc bus voltage of $1856 \mathrm{~V}$-this voltage is normally slightly larger due to a slightly higher than rated incoming bus voltage). The modulation principle and further details are described in [1] and [5]. The phaseshifted multicarrier modulation is modeled as outlined in [1]. The simulation results for the output-voltage waveform and associated fast Fourier transform (FFT) analysis are shown in Fig. 9.

The effective inverter frequency is given by [1]

$$
f_{\mathrm{sw}, \mathrm{inv}}=2 \cdot H \cdot f_{c} \text {. }
$$




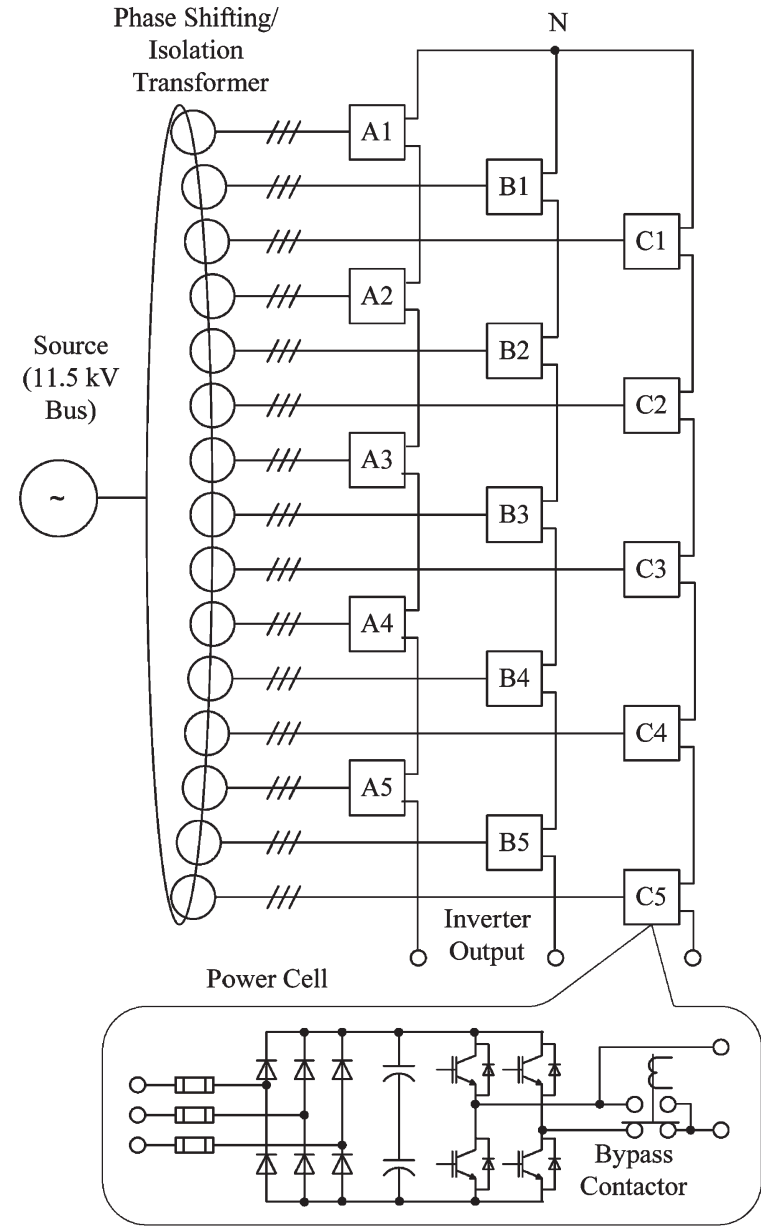

Fig. 8. Multilevel cascaded H-bridge inverter topology to obtain $11-\mathrm{kV}$ (phase-to-phase) output voltage.
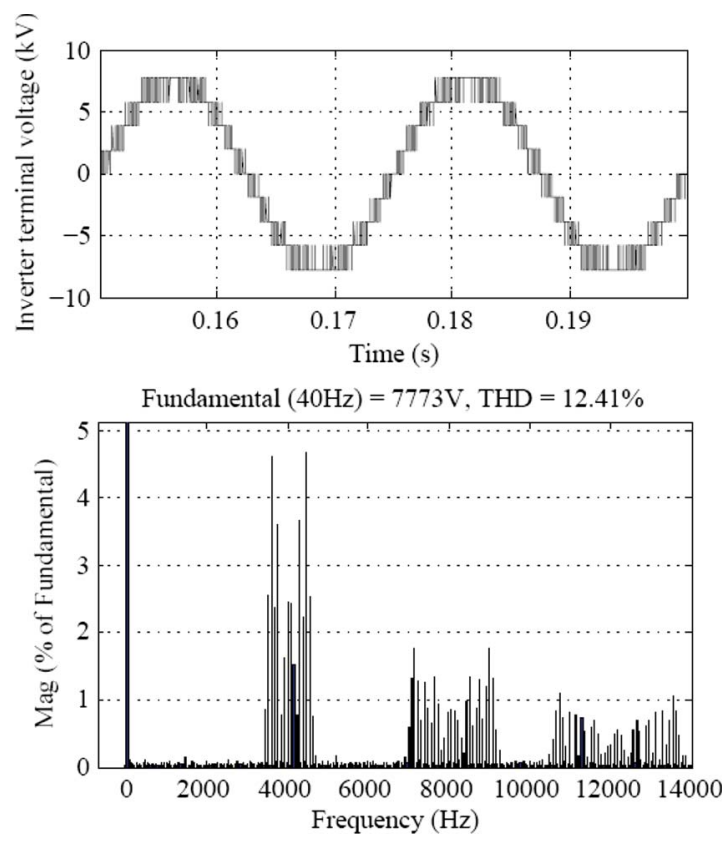

Fig. 9. Simulated inverter output phase-to-neutral voltage (modulating/ fundamental frequency $f_{m}=40 \mathrm{~Hz}, f_{c}=404.5 \mathrm{~Hz}$, modulation index $m_{a}=0.8$ ).

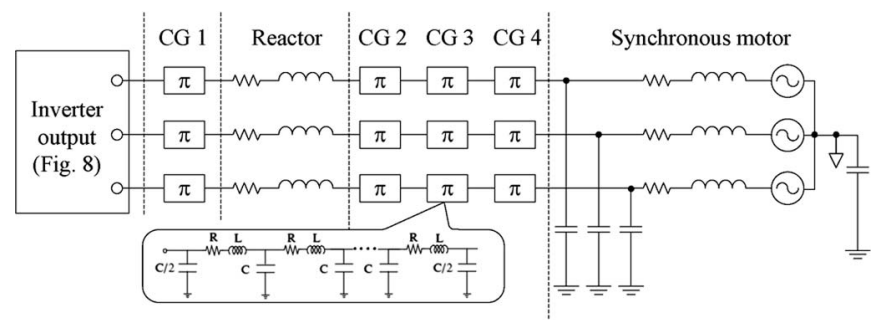

Fig. 10. Load simulation diagram.

The number of cells per phase $(H)$ is five, and the switching/ carrier frequency for each cell $\left(f_{c}\right)$ is $404.5 \mathrm{~Hz}$ (default), resulting in effective inverter frequency $\left(f_{\mathrm{sw}, \text { inv }}\right)$ of $4.05 \mathrm{kHz}$. The effective inverter frequency is also reflected in the frequency spectrum (FFT) in Fig. 9. The inverter is classified as an $11(2 H+1)$ level inverter.

\section{B. Load Modeling}

The load was initially comprehensively modeled, including multiple $\pi$ section transmission lines representing each cable (assuming five sections per cable). The three-phase simulation diagram is shown in Fig. 10, with parameter values in accordance with the Appendix. This cable distributed parameter model approach is valuable to capture the high-frequency overvoltage effects (e.g., at the input of the reactor or at the motor for systems without a reactor). The focus of this paper is, however, on the overvoltages at the motor terminals with the presence of a reactor. Model simplification is investigated for more effective analysis. The reactor and cables between the converter and motor function as a low-pass filter.

The approximate resonant frequency of the reactor and total cable capacitance between the reactor and motor $\left(C_{\mathrm{TC}}\right)$ is used as a first approximation to determine resonant frequency

$$
f_{o}=\frac{1}{2 \cdot \pi \cdot \sqrt{L_{\mathrm{REACTOR}} \cdot C_{\mathrm{TC}}}} .
$$

The resonant frequency $\left(f_{o}\right)$ is calculated as $3.12 \mathrm{kHz}$ using the data in the Appendix. An approximation of the maximum frequency that can be represented by a single $\pi$ model for the longest cable (a cable from CG 4) is given by [21]

$$
f_{m \pi}=\frac{1}{8 \cdot \sqrt{L_{\mathrm{uc}} \cdot C_{\mathrm{uc}}}}
$$

where $L_{\mathrm{uc}}$ is the inductance per unit length $(\mathrm{H} / \mathrm{m})$ and $C_{\mathrm{uc}}$ is the capacitance per unit length $(\mathrm{F} / \mathrm{m})$ of one of the cables from CG4 (refer to the Appendix). This frequency $\left(f_{m \pi}\right)$ is calculated as $19.5 \mathrm{kHz}$ and is well above the effective pass band of the reactor filter since $f_{m \pi} \gg f_{o}$, and therefore, there is no need to model the cables downstream of the reactor as transmission lines with multiple $\pi$ sections. Furthermore, the reactor input frequency/ringing is typically on the order of several hundred kilohertz (measured from TP1 and shown in Fig. 7), and overvoltages due to the transmission line effect can be neglected downstream of the reactor due to the filter effect described earlier. An equivalent lumped load circuit model can therefore be used since the series inductance is large enough. 


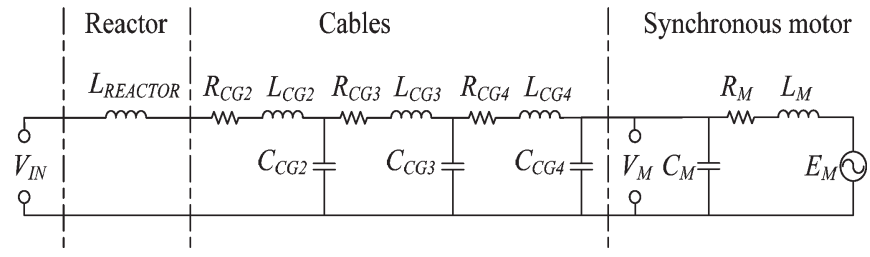

Fig. 11. Single-phase equivalent circuit of the load components.

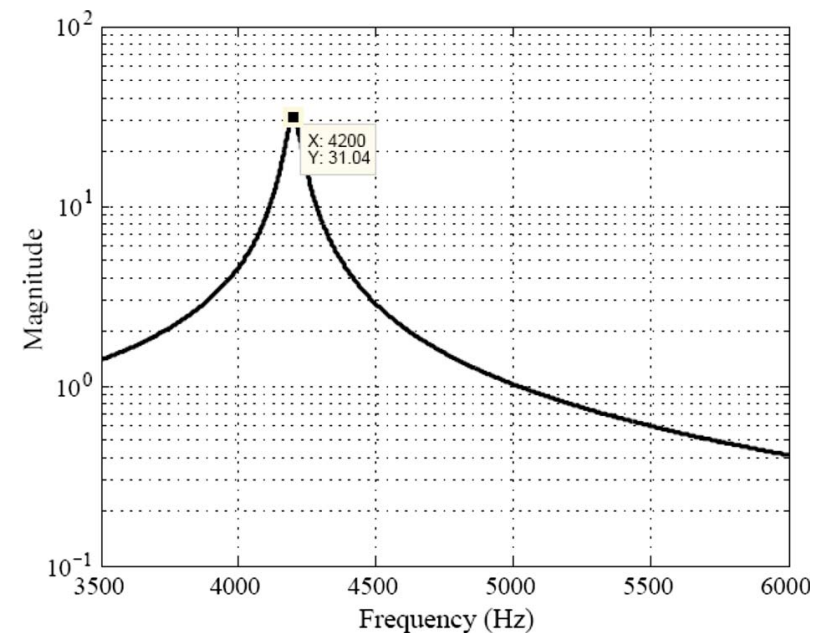

Fig. 12. Magnitude frequency response for $H(j \omega)$.

The simulation model was therefore accordingly simplified, and it was verified that identical results are obtained.

The model can further be simplified into a single-phase equivalent circuit, as shown in Fig. 11, for the purposes of determining the basic voltage transfer function. The values of the circuit parameters are given in the Appendix.

The associated transfer function is given by the following equation, with $V_{M}$ and $V_{I N}$ shown in Fig. 11 and the Bode diagram for the magnitude in Fig. 12:

$$
H(j \omega)=\frac{V_{M}}{V_{I N}}(j \omega) .
$$

In [15], it is stated that the motor impedance does not have a significant influence for a VSI system in terms of the voltage transfer function (with a very long cable). In [13], a basic motor model (represented by a resistor, reactance, and EMF) with a two-level inverter and a step-up transformer was used, and a resonance effect was however described. In [15], the effect of frequency variation has been incorporated in the cable parameters $(L$ and $R$ ) using finite element analysis. The cable length was, however, very long $(30 \mathrm{~km})$. A shorter cable of $800 \mathrm{~m}$ was purely represented by a capacitance in [13]. In this case, the cable length is even shorter (550 m CG4 but with the same order of magnitude capacitance value), and the effect of frequency variation on cable parameter values was therefore not included for the initial evaluation. Furthermore, cable capacitance has a more significant influence on the results than resistance. It has also been shown in [22] and [23] that capacitance typically does not have a significant variation with frequency around the resonant frequency range.

If cable parameter variation with frequency is not considered, a pessimistic result in terms of the voltage transfer function

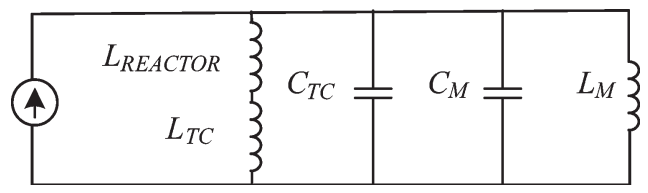

Fig. 13. Simplified single-phase equivalent circuit to determine resonant frequency.

magnitude occurs (i.e., larger values are obtained) [15]. Neglecting the variation does not have a major impact in the resonant frequency. It has been shown in [16] that, for frequencies in the kilohertz range, it is important to include motor winding capacitance (phase to earth) and has therefore been included.

It will be beneficial to determine the resonance frequency for various case studies (e.g., cable lengths). The resonance frequency is the frequency where $|H(j \omega)|$ reaches a peak. The equation for $|H(j \omega)|$ is, however, not simple and not given in this paper, and a further simplification is more practical. Neglecting resistances, the equivalent circuit can be approximated as shown in Fig. 13 (the supply voltage and total inductance are represented as a Thevenin equivalent current source).

The internal EMF of the motor can be neglected since the resonance voltage is far larger than the motor internal EMF. The parallel resonant frequency can now be expressed from the simplified circuit as

$$
f_{r} \approx \frac{1}{2 \cdot \pi \cdot \sqrt{\left(\frac{\left(L_{\mathrm{REACTOR}}+L_{\mathrm{TC}}\right) \cdot L_{M}}{L_{M}+\left(L_{\mathrm{REACTOR}}+L_{\mathrm{TC}}\right)}\right) \cdot\left(C_{\mathrm{TC}}+C_{M}\right)}} .
$$

The approximation results in a resonant frequency of $f_{r}=$ $4.19 \mathrm{kHz}$ and agrees very well with the resonance frequency from the transfer function shown in Fig. 12. This is also consistent with the results from the comprehensive three-phase simulation model.

\section{System Modeling, Explanation, and Results}

Fig. 9 shows drive harmonics at and around the calculated system resonance frequency $(4.2 \mathrm{kHz})$, which can excite overvoltages. Contributing factors are the drive output waveforms, reactor, cable, and motor characteristics (inductances and capacitances). The reactor inductance and high capacitance of the long single-core parallel cables have a major influence on the system resonance frequency. A simulation has been performed to illustrate the resonance phenomenon by using the inverter model output as input to the load model. Internal drive switching transient effects associated with the individual IGBTs have not been included (assumed ideal switching characteristic). Fig. 14 shows simulated results with waveform shapes, which agree well with those of the measured results (Fig. 4).

The test and simulation results are best analyzed in the frequency domain. An FFT conversion has been performed on the measured data to obtain a frequency-domain representation. The same FFT conversion process has been performed on the time-domain simulation results (shown in Fig. 14) for additional verification. The results are shown in Fig. 15.

Good correlation between the simulated and test results is achieved since the amplitudes and frequencies are similar. The amplification of inverter harmonics around the calculated 

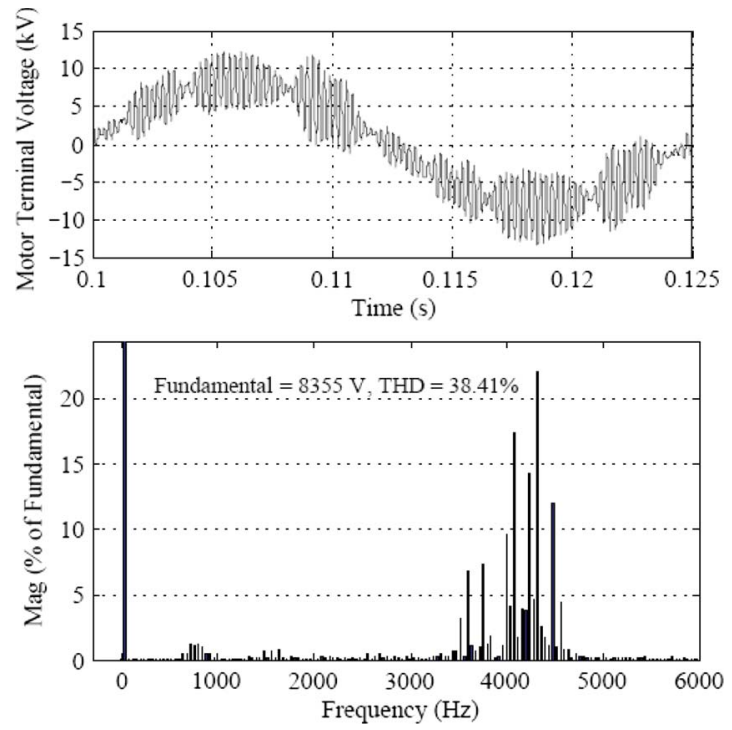

Fig. 14. Simulated motor phase-to-earth voltage $\left(f_{m}=40 \mathrm{~Hz}, f_{c}=\right.$ $\left.404.5 \mathrm{~Hz}, m_{a}=0.8\right)$.

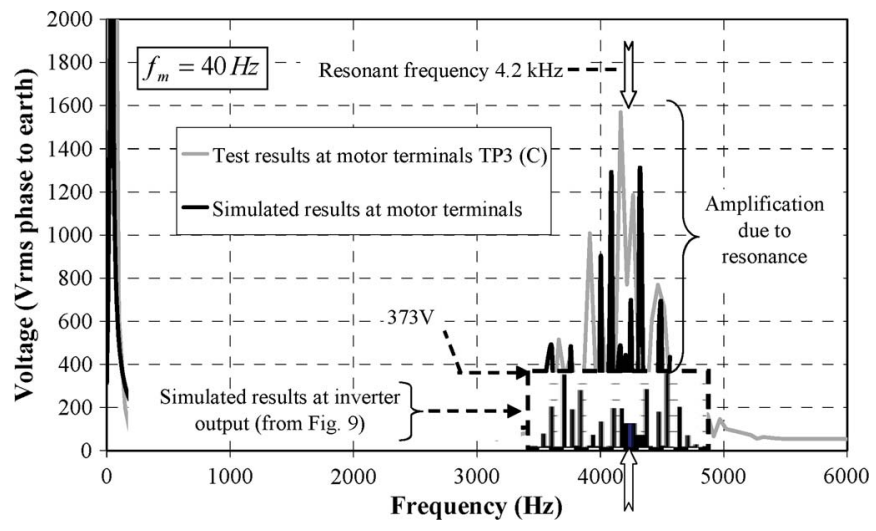

Fig. 15. FFT test and simulation results of motor phase-to-earth voltage ( $\left.f_{m}=40 \mathrm{~Hz}, f_{c}=404.5 \mathrm{~Hz}, m_{a}=0.8\right)$.

resonant frequency (from the transfer function/simplified equation) is clearly visible when compared to Fig. 9. It is acknowledged that the inverter output phase-to-neutral waveform differs slightly in appearance from the inverter phase-to-earth waveform, but the harmonics are still present at the same frequency bands and the cleaner phase-to-neutral waveform is still suitable for the comparison. Fig. 15 also shows that the resonance condition and approximate resonance frequency can easily be determined from test results and knowledge of the inverter output spectrum. The condition is applicable when the test results in the frequency spectrum are significantly larger than that in the inverter output spectrum. The resonant frequency is where the effect of amplification is most severe.

\section{Solution and Simulation Results}

More suitable carrier frequencies, modulation strategies, and a possible filter are solutions that can be considered. Alternative modulation strategies addressing selective harmonic elimination [24] can be investigated. A simple $R C$ filter can be used on the output of the reactor. The carrier-frequency change is the most simplistic solution requiring minimum changes
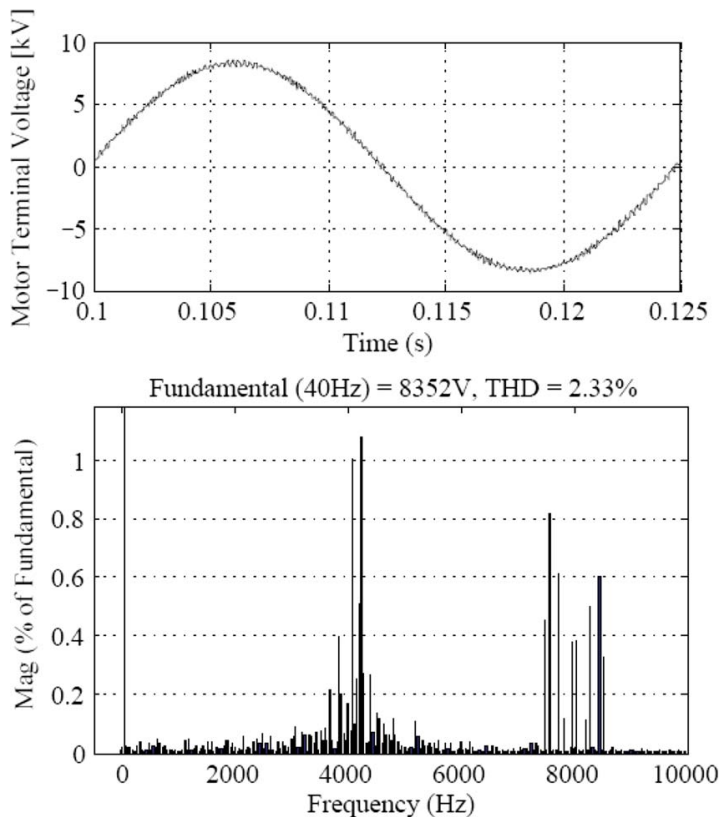

Fig. 16. Simulated motor phase-to-earth voltage $\left(f_{m}=40 \mathrm{~Hz}, f_{c}=800 \mathrm{~Hz}\right.$, $\left.m_{a}=0.8\right)$.

(hardware/software) and will therefore further be considered. The effective inverter switching frequency with a carrier frequency of $404.5 \mathrm{~Hz}$ (default) is $4.05 \mathrm{kHz}$ as previously discussed, with sidebands on the harmonic spectrum around this frequency (other similar lower amplitude sidebands occur at higher multiples of this frequency). In order to avoid the excitation of resonances, the effective inverter frequency should not be close to the system resonant frequency, i.e., it should be at around $2 \mathrm{kHz}$ (or below) or preferably higher than $5 \mathrm{kHz}$ where there is no amplitude amplification in accordance with the transfer function (refer to Fig. 12). The higher frequency option is preferred since higher frequency multiple sidebands would then also be above the resonant frequency. A significantly higher carrier frequency is also preferred due to a reduction in the harmonic distortion in the inverter output waveform, which assists in improving the waveform at the motor terminals. An effective inverter frequency of $8 \mathrm{kHz}\left(f_{c}=800 \mathrm{~Hz}\right)$ was therefore selected. Fig. 16 shows the simulation results with nearsinusoidal waveforms. There is still some simulated resonance at the calculated system resonant frequency, but the magnitude is very small since the exciting harmonics are now extremely small. The manufacturer has confirmed that no inverter derating is required at the higher frequency and that $800 \mathrm{~Hz}$ is also suitable in terms of the processor capability.

\section{Further Test Results and Evaluation}

The process conditions did not allow shutdown of the motor for connection and removal of test equipment at the motor terminals after the carrier-frequency change has been made. Tests were therefore only possible at the output of the reactor (with the synchronization concept [8], test equipment can be connected at the output of the reactor in the synchronized mode, the tests are performed in the desynchronized mode, and the equipment is again removed in the synchronized mode). The 


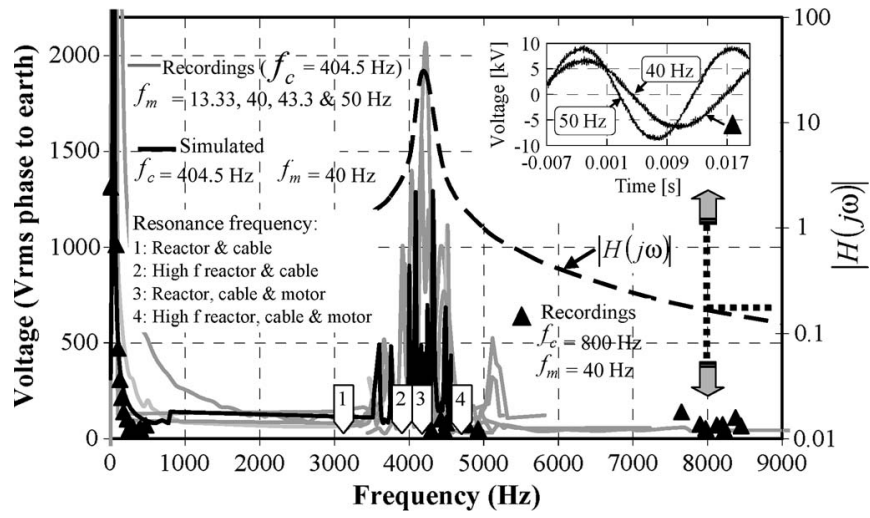

Fig. 17. FFT voltage recordings from field tests before and after the carrierfrequency change.

previous measurements (Fig. 4) indicate that the waveforms at the output of the reactor and at the motor terminals are very similar, as expected. The test results therefore provide an acceptable indication of the effectiveness of the proposed modification, and tests at the motor terminals were not deemed necessary. Fig. 17 shows the measured results which confirm the expected near-sinusoidal waveforms predicted by the simulated results (Fig. 16). Further measured results are also shown at various frequencies, before the carrier-frequency change has been made to show that the resonance phenomenon occurs similarly at different motor frequencies/speeds.

Further simulations were performed by the drive manufacturer by including the effects of high frequency in the reactor and cables (considering the skin effect, by using finite element analysis) with similar simulation results. The high-frequency effects result in a $25 \%(3.9-\mathrm{kHz})$ higher frequency that was calculated initially with (2) mainly due to the reduction in the reactance and capacitance values. The inclusion of the motor parameters also has a significant and additional contribution in the increase in resonant frequency as per (5). The highfrequency cable and reactor parameters result in an approximate $14 \%$ overall increase in the resonance frequency (including the motor) for this case study (i.e., $4.77 \mathrm{kHz}$ ). Fig. 17 shows that the simulation resulted in adequate accuracy, confirming the theory in the previous section. The effect on the calculated resonance frequency by not including high-frequency effects or all parameters is shown in Fig. 17. Even with all parameters and effects included, the approximate resonance frequency remains far off the effective inverter frequency (with the proposed carrier frequency). It can be concluded that the exact high-frequency parameter values are not that important (consistent with the theory in the previous section), particularly if the effective inverter frequency is selected far away the resonance and well above the frequency where no amplitude amplification occurs in accordance with the transfer function. The simulation model and resonance calculation can therefore be used to analyze the resonance effect with further case studies for illustrative purposes.

\section{Further Resonance AnAlysis And CASE Studies}

\section{A. Maximum Overvoltages for the Site Case Study}

The worst case condition is estimated by the simulation in Fig. 18 where the cell carrier frequency has been increased to
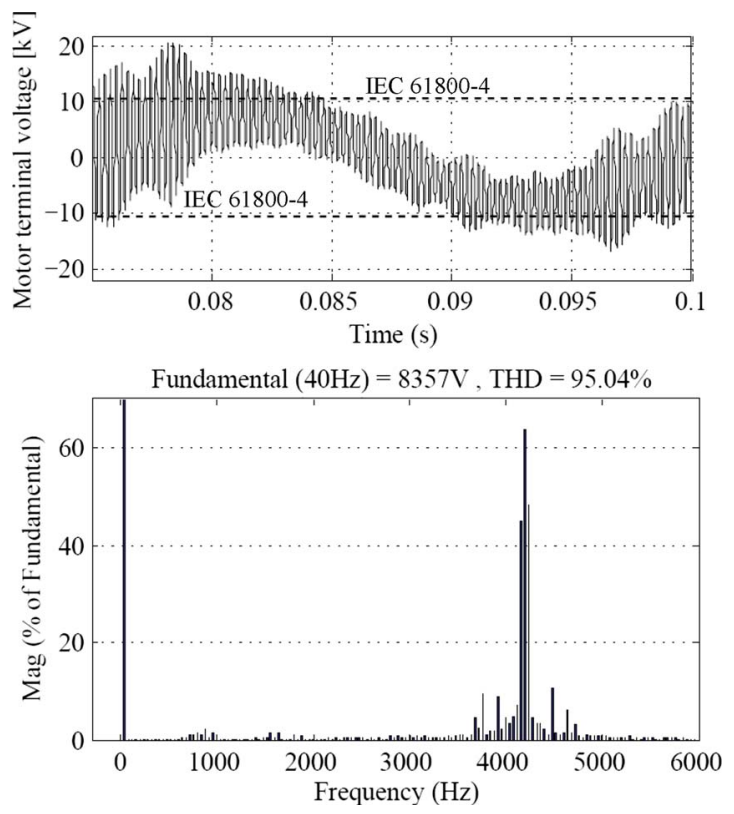

Fig. 18. Simulated motor phase-to-earth voltage $\left(f_{m}=40 \mathrm{~Hz}, f_{c}=420 \mathrm{~Hz}\right.$, $\left.m_{a}=0.8\right)$.

$420 \mathrm{~Hz}$ to obtain an effective inverter frequency of $4.2 \mathrm{kHz}$ at the system resonance frequency. Fig. 18 shows severe peak phase-to-earth voltages of approximately $20 \mathrm{kV}$, which could have been expected, i.e., almost two times the maximum voltage stipulated by IEC 61800-4 for normal motors.

\section{B. Effect of Cable Length, Reactor, and Motor}

Equation (5) can effectively be used to estimate the effect of cable length with and without the reactor. The parameters for the cables, motor, and reactor are given in Table I. Total cable capacitance, inductance, and resistance are calculated on the same basis as was done in Table II. It is assumed that the cable size/quantity does not increase with length to compensate for increased voltage drop. This may only be applicable for extremely long cables since a large derating factor for the cables has been applied associated with the ampacity calculations. The results are shown in Fig. 19. The figure shows that with the default carrier frequency, resonance would have occurred with the case study motor $(17 \mathrm{MW})$ at the effective inverter frequency $(4 \mathrm{kHz}$ ) when the cable length is $600 \mathrm{~m}$. An associated simulation has been performed, with results shown in Fig. 20.

Similarly to the results in Fig. 18, overvoltages reach approximately two times the maximum allowed by IEC 61800-4. Fig. 19 also shows resonance that can occur with short cable lengths, e.g., with the parameters and simulation results shown in Fig. 21. It can be observed that the resonance condition is more severe since less damping is applicable due to the lower resistance with the shorter cable.

Fig. 19 shows that resonance without a reactor is only likely at significantly longer cable distances, e.g., several kilometers (approximately $3 \mathrm{~km}$ in the case study with the default carrier frequency). Resonance with smaller motors (without a reactor) is even less likely (Fig. 19). Very long cable distances are required to create a potential resonance condition in this case. Furthermore, potential resonance also decreases with 
TABLE I

CABle, Motor, AND Reactor Parameters

\begin{tabular}{|c|c|c|c|c|c|c|c|c|c|}
\hline $\begin{array}{l}\text { Cable } \\
\text { Group } \\
(C G)\end{array}$ & $\begin{array}{c}\text { Number } \\
\text { of single } \\
\text { core } \\
\text { cables } \\
\text { per phase } \\
\quad\left(n_{c}\right)\end{array}$ & $\begin{array}{c}\text { Cross } \\
\text { Sectional } \\
\text { Copper } \\
\text { Area }\left(\mathrm{mm}^{2}\right)\end{array}$ & $\begin{array}{l}\text { Length of } \\
\text { each } \\
\text { single } \\
\text { core } \\
\text { cable } \\
(l) \\
\text { (m) } \\
\end{array}$ & $\begin{array}{l}\text { Resistance } \\
\left(R_{u c}\right) \text { per } \\
\text { single core } \\
\text { cable unit } \\
\text { length } \\
(\Omega / \mathrm{km})\end{array}$ & $\begin{array}{l}\text { Inductance } \\
\left(L_{u c} \cdot 10^{3}\right) \\
\text { per single core } \\
\text { cable unit } \\
\text { length } \\
(\mathrm{mH} / \mathrm{km})\end{array}$ & $\begin{array}{c}\text { Capacitance } \\
\left(C_{u c} \cdot 10^{9}\right) \\
\text { per single } \\
\text { core cable } \\
(\mathrm{nF} / \mathrm{km})\end{array}$ & $\begin{array}{c}\text { Total } \\
\text { resistance for } \\
\text { cable group } \\
\left(R_{C G}=\right. \\
\left.l \cdot R_{u c} 10^{-3} / n_{c}\right) \\
(\Omega)\end{array}$ & $\begin{array}{c}\text { Total } \\
\text { inductance } \\
\text { for cable } \\
\text { group } \\
\left(L_{C G} \cdot 10^{-3}=\right. \\
\left.l \cdot L_{u c} \cdot 10^{-3} / n_{c}\right) \\
(\mathrm{mH}) \\
\end{array}$ & $\begin{array}{c}\text { Total } \\
\text { capacitance for } \\
\text { cable group } \\
\left(\mathrm{C}_{\mathrm{CG}} \cdot 10^{-9}=\right. \\
\left.l \cdot C_{u c} \cdot n_{c} \cdot 10^{-3}\right) \\
(\mathrm{nF})\end{array}$ \\
\hline 1 & 2 & 500 & 22 & 0.051 & 0.299 & 454 & 0.00056 & 0.003291 & 19.976 \\
\hline 2 & 3 & 240 & 70 & 0.098 & 0.325 & 345 & 0.00229 & 0.007576 & 72.45 \\
\hline 3 & 2 & 240 & 23 & 0.098 & 0.325 & 345 & 0.00113 & 0.003734 & 15.87 \\
\hline 4 & 4 & 500 & 550 & 0.051 & 0.299 & 454 & 0.00701 & 0.041142 & 998.8 \\
\hline \multicolumn{10}{|c|}{ Total values between reactor and motor terminals } \\
\hline \multicolumn{4}{|c|}{$\begin{array}{c}\text { Resistance } \\
R_{T C}=R_{C G 2}+R_{C G 3}+R_{C G 4} \\
(\Omega)\end{array}$} & \multicolumn{3}{|c|}{$\begin{array}{c}\text { Capacitance } \\
C_{T C}=C_{C G 2}+C_{C G 3}+C_{C G 4} \\
(\mathrm{~F}) \\
\end{array}$} & \multicolumn{3}{|c|}{$\begin{array}{c}\text { Inductance } \\
L_{T C}=L_{C G 2}+L_{C G 3}+L_{C G 4} \\
(\mathrm{H})\end{array}$} \\
\hline \multicolumn{4}{|c|}{0.0104} & \multicolumn{3}{|c|}{$1.09 \cdot 10^{-6}$} & \multicolumn{3}{|c|}{$5.25 \cdot 10^{-5}$} \\
\hline
\end{tabular}

TABLE II

Cable Data and Calculations

\begin{tabular}{|c|c|c|c|c|c|c|}
\hline \multicolumn{3}{|c|}{ Motor } & \multicolumn{3}{c|}{ Cable } \\
\hline Rating & Type & $\begin{array}{c}\text { Inductance } \\
\mathrm{mH}\end{array}$ & $\begin{array}{c}\text { Capacitance } \\
\mathrm{nF}\end{array}$ & Description & $\begin{array}{c}\text { Capacitance } \\
\mathrm{nF} / \mathrm{km}\end{array}$ & $\begin{array}{c}\text { Inductance } \\
\mathrm{mH} / \mathrm{km}\end{array}$ \\
\hline 0.2 & Induction & 100.00 & 30 & $1 \times 3 \mathrm{c} 25 \mathrm{~mm}^{2}$ & 201 & 0.395 \\
1 & Induction & 30.81 & 50 & $1 \times 3 \mathrm{c} 95 \mathrm{~mm}^{2}$ & 308 & 0.318 \\
9.4 & Induction & 2.76 & 159 & $3 \times 2 \times 1 \mathrm{cx} 500 \mathrm{~mm}^{2}$ & 454 & 0.299 \\
17 & Synchronous & 1.80 & 302 & $3 \times 4 \times 1 \mathrm{c} 500 \mathrm{~mm}^{2}$ & 454 & 0.299 \\
23 & Synchronous & 3.30 & 350 & $3 \times 4 \times 1 \mathrm{c} 500 \mathrm{~mm}^{2}$ & 454 & 0.299 \\
36 & Synchronous & 2.42 & 450 & $3 \times 5 \times 1 \mathrm{c} 500 \mathrm{~mm}^{2}$ & 454 & 0.299 \\
55 & Synchronous & 0.86 & 500 & $3 \times 7 \times 1 \mathrm{c} 500 \mathrm{~mm}^{2}$ & 454 & 0.299 \\
\hline
\end{tabular}

Notes

$3 \%$ reactor (with motor rating as base) used for all motors

Typical motor capacitances used (the cable capacitance, reactor impedance and motor impedance have a more significant influence on the resonance frequency)

All cables are XLPE $\mathrm{Cu}$ and values are given per individual cable

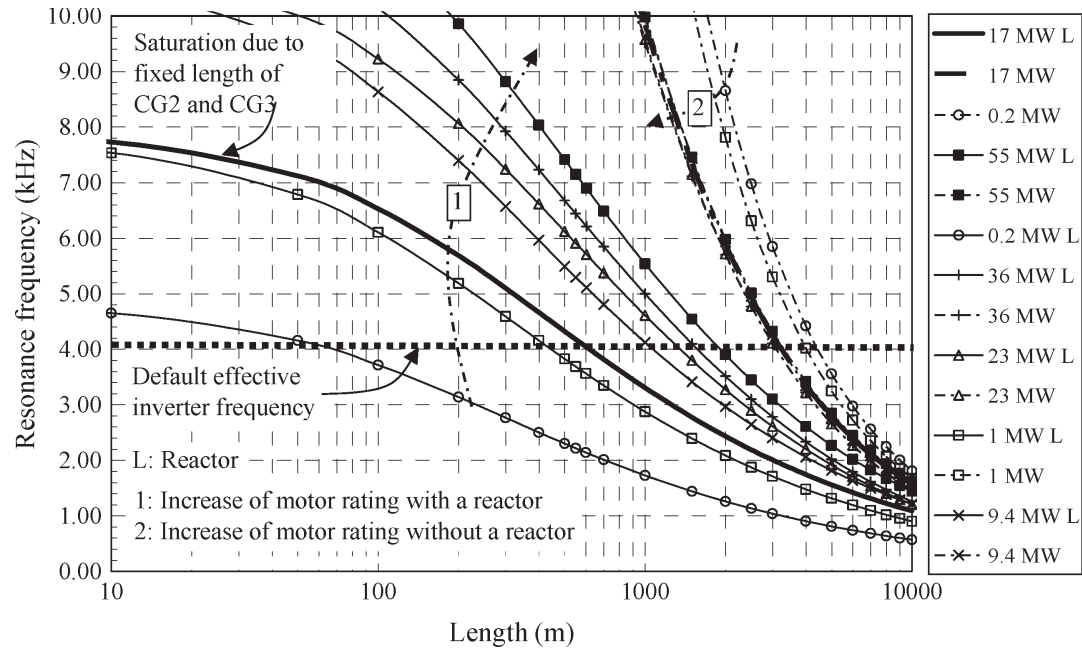

Fig. 19. Effect of cable length, motor rating, and reactor on the resonance frequency. 

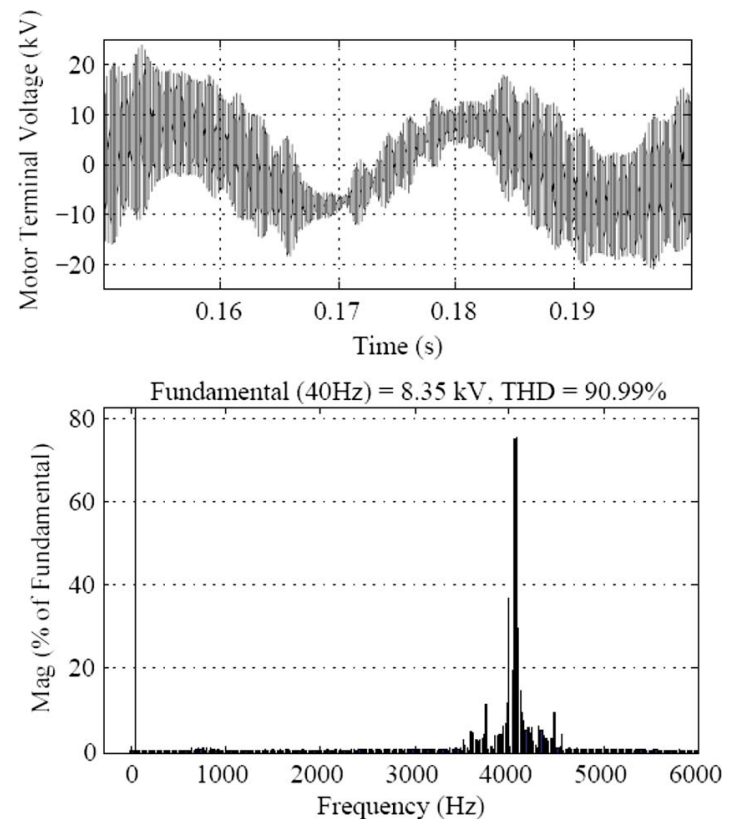

Fig. 20. Simulated motor phase-to-earth voltage $\left(f_{m}=40 \mathrm{~Hz}, f_{c}=\right.$ $\left.404.5 \mathrm{~Hz}, m_{a}=0.8, l=600 \mathrm{~m}\right)$.
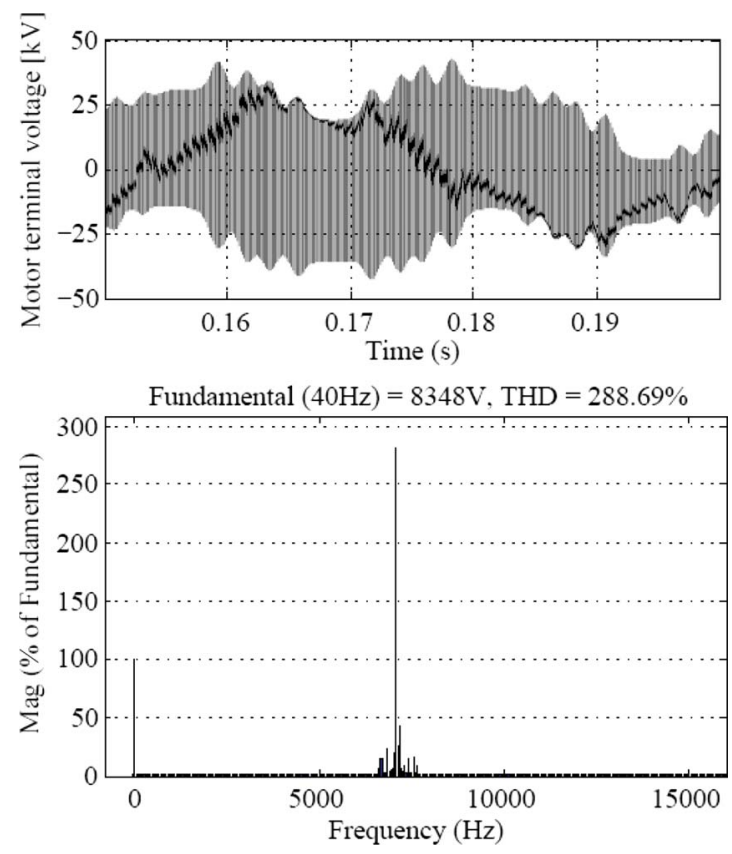

Fig. 21. Simulated motor phase-to-earth voltage $\left(f_{m}=40 \mathrm{~Hz}, f_{c}=712 \mathrm{~Hz}\right.$, $\left.m_{a}=0.8, l=50 \mathrm{~m}\right)$.

smaller motors with reactors since it is more likely for the system resonance frequency to be below the effective inverter frequency, particularly for longer cable lengths. VSI-ML-H systems have traditionally been used more commonly for lower power motors, shorter cable lengths, and smaller excitation voltages (due to the smaller voltage steps with lower voltage systems), making the possibility of resonance extremely rare, and this is possibly why the phenomenon has not been widely published. Large motor systems with reactors are far more likely to suffer from resonance conditions, since with typical cable lengths, the system resonance frequency is likely to be close to or in the region of the effective inverter frequency.

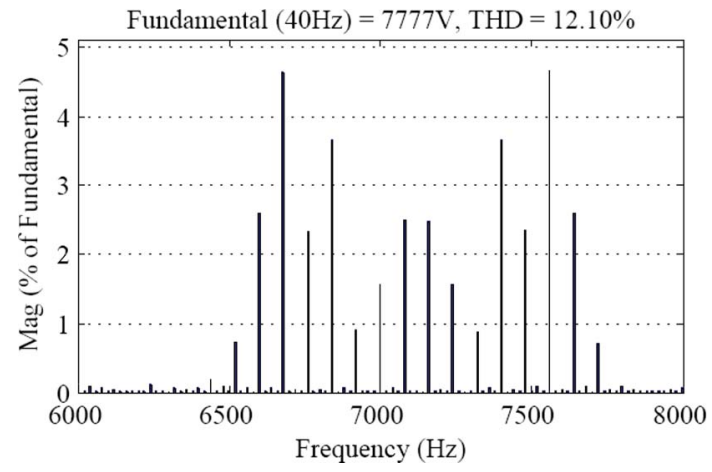

Fig. 22. Simulated inverter phase-to-neutral voltage spectrum band around the effective inverter frequency $\left(f_{m}=40 \mathrm{~Hz}, f_{c}=712 \mathrm{~Hz}, m_{a}=0.8\right)$.

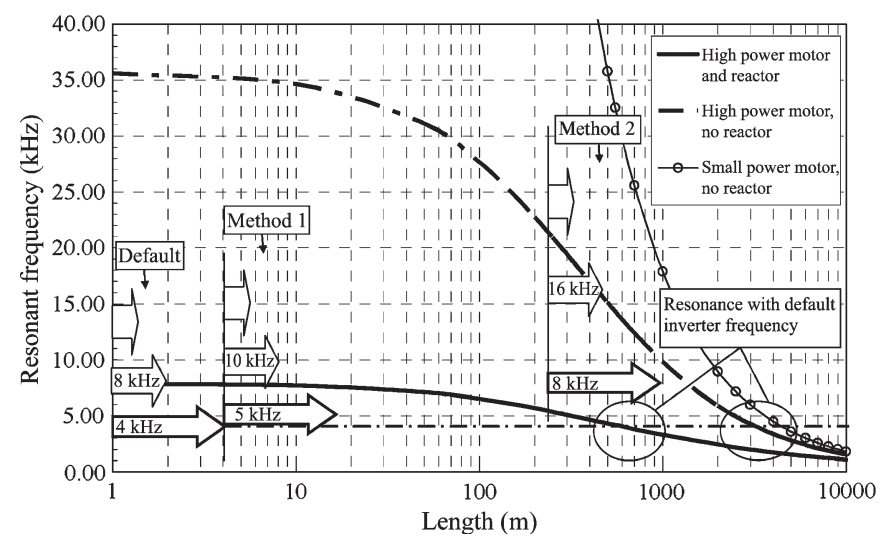

Fig. 23. Carrier-frequency selection.

\section{Carrier-Frequency Considerations}

Several options can be considered to eliminate resonance conditions, with the carrier-frequency change options as the preferred solution as previously discussed. Furthermore, carrier-frequency change methods are evaluated. In Method 1, the effective inverter frequency and its harmonic band (Fig. 22 shows a zoomed-in example of the lower harmonic band) are selected below the resonant frequency while ensuring that the higher order harmonic bands are above the resonant frequency. This is shown in Fig. 23, and the bold arrows represent the harmonic bands (based on the inverter modeling-Fig. 4). The benefit of this method is that the effective inverter frequency is low and therefore benefits from overall lower inverter losses. This method is more applicable for short cable lengths due to higher resonance frequencies. Fig. 24 shows a simulation example with acceptable results by using Method 1 (note the potential improvement compared to Fig. 21).

In the case of longer cable lengths (large motors), the effective inverter frequency band is typically in the range of the resonance frequency, and it is necessary to increase the inverter frequency to ensure that the band is above the resonance frequency (Method 2 shown in Fig. 22). The higher order harmonic bands are then also above the resonant frequency. This method can also be used for very long cable distances (e.g., $3000 \mathrm{~m}$ ) without a reactor. Method 2 can be used in most cases if the higher carrier frequency is acceptable (considering that for short cable distances, it implies a high carrier frequency). It has been shown in [25] that the VSI-ML-H topology is 

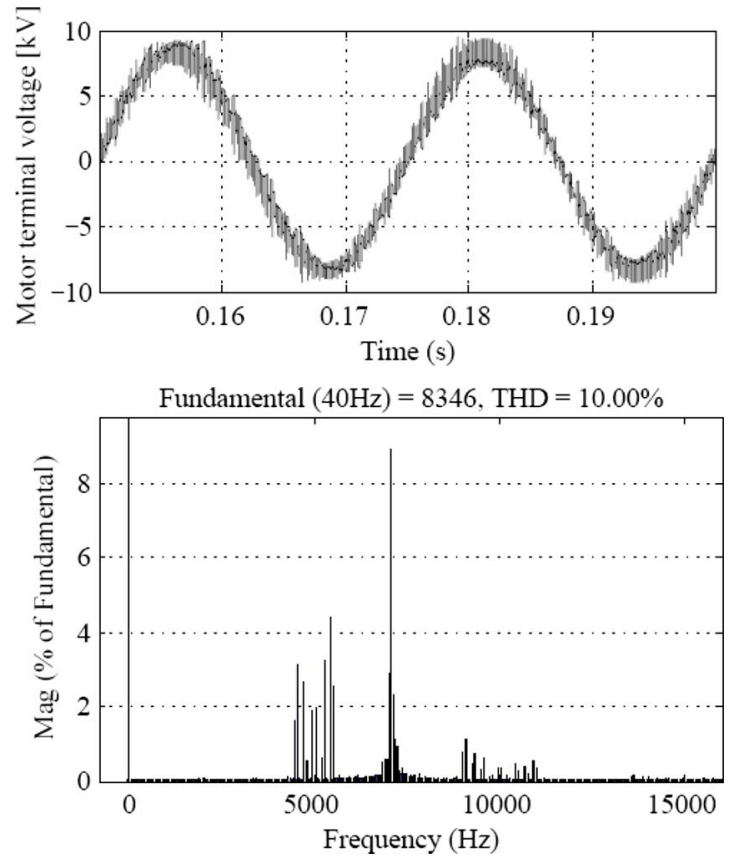

Fig. 24. Simulated motor phase-to-earth voltage $\left(f_{m}=40 \mathrm{~Hz}, f_{c}=500 \mathrm{~Hz}\right.$, $\left.m_{a}=0.8, l=50 \mathrm{~m}\right)$.

superior to other VSI topologies regarding the maximum carrier frequency and associated losses. Significantly higher carrier frequencies can be realized than shown in the actual case study but with an associated increase in converter losses with typical losses shown in [25]. In most cases with a reactor and long cable distances, Method 2 should be considered since a very high carrier frequency should not be required. In most cases without a reactor with typical cable lengths (e.g., below $1000 \mathrm{~m}$ ), it should not be necessary to increase the carrier frequency (see Fig. 19).

Fig. 23 was used as an example showing the general proposed approach. The actual selection of the inverter frequency should however be done on a case-by-case evaluation for the specific application. The approach in Fig. 23 can also be used when other methods are available, e.g., to determine the harmonics in the resonance area to be eliminated or to be reduced with selective harmonic elimination [24]. In the case of some current source converter topologies, e.g., the load commutated inverter topology, a carrier-frequency change is not applicable and a suitable filter (e.g., $R C$ filter) will have to be added to reduce the excitation of resonances. The removal of the reactor is another alternative if break-before-make transfers can be accommodated.

\section{CONCLUSion AND RECOMmEndations}

Field test results show that unacceptable overvoltage effects can occur in MV (11-16-kV) multilevel drive systems, ultimately leading to premature motor failure and associated production losses. Motor voltages associated with high-frequency traveling waves may be a concern in some cases with larger voltage steps associated with higher voltage output drives (in systems without a synchronization reactor). Resonance overvoltages can be far more severe than traveling-wave overvoltages. Surge counter test equipment used to detect overvoltage problems is not effective to detect resonance overvoltage conditions. It is therefore recommended to perform oscilloscope tests as well. Simulation and subsequent test results show that the resonance effects can be minimized with the implementation of an optimal carrier frequency. The effect of model complexity and parameter variation with frequency has been investigated, showing simplification opportunities. A simplified model was therefore developed to show potential worst case resonance scenarios. A simplified calculation method was developed, which can be used to conveniently determine suitable carrier frequencies to avoid resonance. Overvoltages associated with smaller motor lower voltage VSI-ML-H drive applications (e.g., $6.6 \mathrm{kV}$ ) are unlikely to be associated with unacceptable traveling-wave or resonance overvoltages. It has been shown that potential resonance becomes more likely with larger drive systems with reactors.

High-power applications are becoming more in demand and are mostly process critical, and a bypass configuration is often advised. Multiple motor applications are often encountered. A synchronization reactor is typically used in these systems, and the overvoltage problem can effectively be addressed by the selection of the correct carrier frequency to avoid resonances. The reactor also eliminates the possibility of travelling-wave overvoltages at the motor terminals. Existing and new motors with a high rated voltage and with normal insulation can now therefore benefit from large ASD technology.

Break-before-make transfers (no reactor required) or selective harmonic elimination can be considered as an alternative to the carrier-frequency change method in applications requiring an unacceptably high carrier frequency (where increased converter losses cannot be accommodated).

\section{APPENDIX}

The manufacturer specifications for the capacitor divider sensor are as follows:

bandwidth

rated voltage

$6 \mathrm{~Hz}-8 \mathrm{MHz}$

hi-pot voltage ratings

$16 \mathrm{kV}$

$33 \mathrm{kV}$ ac rms, $150 \mathrm{kV}$ dc, $150 \mathrm{kV}$ impulse;

capacitance values $\quad 80 \mathrm{pF}(C 1)$ and $20 \mathrm{nF}(C 2)$;

divider ratio $251(C 1+C 2) / C 1$.

A correction factor of 1.1 was applied to match the results from the pretested resistive divider circuit, representing a conservative approach. The manufacturer specifications for the recording equipment are as follows:

oscilloscope $500 \mathrm{MHz}$;

surge counter Pulses with rise times $\leq 1.5 \mu \mathrm{s}$.

The simulation parameters are as follows.

1) The XLPE cable data and calculations for the total equivalent parameters are given in Table I.

2) The reactor value used is $L_{\text {REACTOR }}=0.0024 \mathrm{H}$ (reactor resistance is neglected).

3) The 17-MW motor parameters used are as follows: $L_{M}=$ $0.0018 \mathrm{H}, R_{M}=0.02 \Omega$, and $C_{M}=3.02 * 10^{-7} \mathrm{~F}$ (phase to earth). The $C_{M}$ value is from a manufacturer for the approximate machine size; this value is not as important since the total cable capacitance is significantly 
larger. The neutral-to-earth capacitance value has been assumed to be the same, which has a negligible effect on the simulation results.

\section{ACKNOWLEDGMENT}

The authors would like to thank R. Pretorius (Rapha Pretorius Associates) for the tests with the resistive divider circuitry, B. van Tonder (Sasol Synfuels) for test support, A. Maritz (Sasol Synfuels) for funding the tests, M. Rastogi (Siemens) for performing additional simulations and technical evaluation of a higher carrier frequency (temperature conformance, rating, and processing capability), B. van Blerk (Sasol Synfuels) for PLC support during testing, M. Naude (Mittal Steel) for providing the capacitive divider circuitry, and IRIS power for recording equipment software and specifications.

\section{REFERENCES}

[1] B. Wu, High Power Converters and AC Drives. Piscataway, NJ: IEEE Press, 2006.

[2] J. Rodríguez, J. Lai, and F. Z. Peng, "Multilevel inverters: A survey of topologies, controls, and applications," IEEE Trans. Ind. Electron., vol. 49, no. 4, pp. 724-738, Aug. 2002.

[3] B. Lockley, B. Wood, and R. Paes, "IEEE Std. 1566-The need for a large adjustable speed drive standard," in Proc. IEEE PCIC, 2006, pp. 1-10.

[4] P. Hammond, "A new approach to enhance power quality for medium voltage AC drives," IEEE Trans. Ind. Appl., vol. 33, no. 1, pp. 202-208, Jan./Feb. 1997.

[5] J. Rodríguez, P. W. Hammond, J. Pontt, R. Musalem, P. Lezana, and M. J. Escobar, "Operation of a medium-voltage drive under faulty conditions," IEEE Trans. Ind. Electron., vol. 52, no. 4, pp. 1080-1085, Aug. 2005.

[6] J. Rodríguez, L. Morán, J. Pontt, J. L. Hernández, L. Silva, C. Silva, and P. Lezana, "High-voltage multilevel converter with regeneration capability," IEEE Trans. Ind. Electron., vol. 49, no. 4, pp. 836-839, Aug. 2002.

[7] D. Eaton, J. Rama, and A. Macak, "Zero downtime-Five years of operation w/ new adjustable speed electric drive on critical non-spared compressors," in Proc. IEEE PCIC, Sep. 2006, pp. 1-7.

[8] F. Endrejat and P. Pillay, "The soft starters-adjustable speed systems for multiple MW rated motors," IEEE Ind. Appl. Mag., vol. 14, no. 6, pp. 2737, Nov./Dec. 2008.

[9] W. Chen, G. Gao, and C. A. Mouton, "Stator insulation system evaluation and improvement for medium voltage adjustable speed drive applications," in Proc. IEEE PCIC, 2008, pp. 1-7.

[10] M. K. W. Stranges, G. C. Stone, and D. L. Bogh, "Progress on IEC 6003418-42 for qualification of stator insulation for medium-voltage inverter duty applications," in Proc. IEEE PCIC, Sep. 2007, pp. 1-7.

[11] F. Endrejat, B. van Blerk, and G. Vignolo, "Experience with new large adjustable speed drive technology for multiple synchronous motors," in Proc. PCIC Eur., 2008, pp. 196-205.

[12] J. A. Oliver and G. C. Stone, "Implications for the application of adjustable speed drive electronics to motor stator winding insulation," IEEE Electr. Insul. Mag., vol. 11, no. 4, pp. 26-32, Jul./Aug. 1995.

[13] J. Rodríguez, J. Pontt, C. Silva, R. Musalem, P. Newman, R. Vargas, and S. Fuentes, "Resonances and overvoltages in a medium-voltage fan motor drive with long cables in an underground mine," IEEE Trans. Ind. Appl., vol. 42, no. 3, pp. 856-863, May/Jun. 2006.

[14] G. Saggewiss, R. Kotwitz, and D. J. McIntosh, "AFD synchronizing applications: Identifying potential methods and benefits," in Proc. IEEE PCIC, 2001, pp. 83-89.

[15] R. O. Raad, T. Henriksen, H. Raphael, and A. Hadler-Jacobsen, "Converter-fed subsea motor drives," IEEE Trans. Ind. Appl., vol. 32, no. 5, pp. 1069-1079, Sep./Oct. 1996.

[16] M. Berth, L. Küng, and E. F. D. E. Limbeck, "Switching overvoltages in motor circuits," IEEE Trans. Ind. Appl., vol. 37, no. 6, pp. 1582-1589, Nov./Dec. 2001.
[17] Adjustable Speed Electrical Power Drive Systems-Part 4: General Requirements-Rating Specifications for a.c. Power Drive Systems Above $1000 \mathrm{~V}$ a.c. and Not Exceeding 35 kV, IEC 61800-4, 2002.

[18] M. Kaufhold, K. Schäfer, K. Bauer, and M. Rossmann, "Medium and high power drive systems; Requirements and suitability proof for winding insulation systems," in Proc. INSUCON, 2006, pp. 86-92.

[19] R. J. Kerkman, D. Leggate, and G. L. Skibinski, "Interaction of drive modulation and cable parameters on AC motor transients," IEEE Trans. Ind. Appl., vol. 33, no. 3, pp. 722-731, May/Jun. 1997.

[20] A. F Moreira, T. A. Lipo, G. Venkataramanan, and S. Bernet, "Highfrequency modeling for cable and induction motor overvoltage studies in long cable drives," IEEE Trans. Ind. Appl., vol. 38, no. 5, pp. 1297-1306, Sep./Oct. 2002.

[21] Matlab Simulink, Version 7 Release 14, Transmission Line Model Notes

[22] R. Wetter, B. Kawabani, and J. Simond, "Voltage stresses on PWM inverter fed induction motors: Cable modeling and measurement," in Proc. ICEM, 2004, CD-ROM, Paper 273.

[23] P. Mäki-Ontto, H. Kinnunen, and J. Luomi, "AC motor cable model for bearing current and over-voltage analysis," in Proc. ICEM, 2004 , CD-ROM, Paper 367.

[24] L. Li, D. Czarkowski, Y. Liu, and P. Pillay, "Multilevel selective harmonic elimination PWM technique in series-connected voltage inverters," IEEE Trans. Ind. Appl., vol. 36, no. 1, pp. 160-170, Jan./Feb. 2000.

[25] S. S. Fazel, "Investigation and comparison of multi-level converters for medium voltage applications," Dr. Ing dissertation, Technische Universität Berlin, Berlin, Germany, 2007.

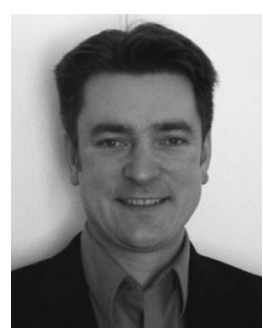

Frieder Endrejat (M'06-SM'09) received the B.Eng. and the M.Eng. degrees in electrical engineering from the University of Pretoria, Pretoria, South Africa, in 1997 and 1999, respectively.

He has been with Sasol Technology, Secunda, South Africa, since 1999. He was responsible for several petrochemical plant power system projects and provided specialized engineering consulting services in the field of electrical drives, machines, and earthing systems. He was the originator of the Sasol specification for medium-voltage adjustable-speed drives. Currently, he holds the position of Principal Engineer and is responsible for power system projects incorporating large drive systems.

Mr. Endrejat is a senior member of the South African Institution for Electrical Engineers and a Registered Professional Engineer in South Africa.

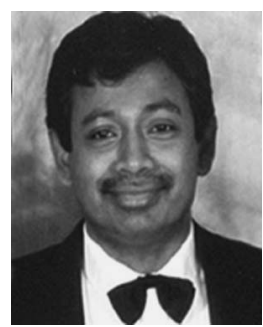

Pragasen Pillay (S'84-M'87-SM'92-F'05) received the B.S. and M.S. degrees from the University of KwaZulu-Natal, KwaZulu-Natal, South Africa, in 1981 and 1983, respectively, and the Ph.D. degree from Virginia Polytechnic Institute and State University, Blacksburg, in 1987, while funded by a Fulbright Scholarship.

From January 1988 to August 1990, he was with the University of Newcastle upon Tyne, U.K. From August 1990 to August 1995, he was with the University of New Orleans, New Orleans, LA. Thereafter, he was a Professor with the Department of Electrical and Computer Engineering, Clarkson University, Potsdam, NY. Since 1999, he has been an Adjunct Professor with the University of Cape Town, Rondebosch, South Africa. He is currently a Professor and Hydro-Québec Senior Chair in the Department of Electrical and Computer Engineering, Concordia University, Montreal, QC, Canada. His research and teaching interests include modeling, design, and control of electric motors and drives for industrial and alternate energy applications and power quality.

Dr. Pillay is a member of the IEEE Power Engineering, IEEE Industry Applications, IEEE Industrial Electronics, and IEEE Power Electronics Societies. $\mathrm{He}$ is a member of the Electric Machines Committee and past Chairman of the Industrial Drives Committee within the IEEE Industry Applications Society, and past Chairman of the Induction Machinery Subcommittee in the IEEE Power Engineering Society. He is a Fellow of the Institution of Electrical Engineers, U.K., and a Chartered Electrical Engineer in the U.K. He is also a member of the Academy of Science of South Africa. 